\title{
Increasing Student Practical Experience with the Hurdle of Large Class Sizes
}

\author{
James Baleshta, \\ Department of Mechanical and Mechatronics Engineering, University of Waterloo, \\ jrbalesh@uwaterloo.ca
}

\begin{abstract}
Many students entering Mechanical or Mechatronics Engineering (MME) at the University of Waterloo (UWaterloo) have limited hands-on skills and lack practical technical knowledge. Student surveys cite a desire for increased practical experience within the curriculum.

This paper presents an initiative to address this issue. A keychain project was designed to involve all first year MME students in a practical (hands-on) activity that would foster competence with machinery. This objective proved difficult to implement due to large student enrollment, where scheduling, supervision, and resources were all significant challenges. However, as a result of this experience, over 400 engineering students were provided early exposure to the Student Machine Shop, creating a desire and confidence to pursue additional experience.

This program is expected to continue at UWaterloo and become a component of a wider engineering clinic initiative. The methodology and key takeaways will be discussed herein.
\end{abstract}

Keywords: hands-on, practical experience, peer intimidation, engineering clinic.

\section{INTRODUCTION}

Students accepted into the Mechanical and Mechatronics Engineering program at the University of Waterloo have diverse backgrounds and a wide range of technical proficiency. It soon becomes evident, however, that the mid-point of this range is low; many students exhibit a low degree of basic mechanical skill. Outside of specialty student teams, the undergraduate curriculum does not currently offer sufficient opportunity to increase practical experience to the level of student expectation. Results of graduating exit surveys taken from 2010 2013 for both Mechanical (ME) and Mechatronics (MTE) streams clearly expressed a desire for increased practical experience in the curriculum [3]. The top three courses selected by students as the most important in their engineering academic program included either practical and/or hands-on experience as the basis for their selection. MTE students surveyed for their "Least Met Expectations" responded with "a lack of practical skills" while ME students cited "the lack of hands-on experience and machining opportunity." Co-operative education work placements, which are integral to the UWaterloo experiential learning experience, were valued for their practical experience.

The imbalance between theoretical and practical knowledge development is not new or unique to UWaterloo. Sheppard and Jenison (1999) reported that engineering schools in the United States were criticized for offering too few practical and hands-on courses. They indicated that engineering education began to transition from a practical to a more scientific or theoretical foundation in the 1950s, as hands-on experiences were gradually replaced with additional science and math components [6]. Student experience in first year engineering courses impacts the rates of attrition and failure. [1] [5]. A heavy theoretical base, without any hands-on approach ("theory-first, practical-afterwards") is seen as a cause of students losing enthusiasm, hope and dreams of technical accomplishment [9]. As a response, hands-on engineering programs have been integrated at some institutions to improve the student experience. [2][7]. In addition, meaningful hands-on activities were perceived as an "essential" provision in a program to attract female students to (transportation) engineering) [4].

Students are often placed in manufacturing positions during their co-operative work terms, where they interact extensively with maintenance workers, other technical staff and contractors. Entering these roles with minimal hands-on skill and little practical technical knowledge places these students at a significant disadvantage. Given that all Engineering students at UWaterloo commence their first co-operative placements following their $1 \mathrm{~A}$ or $1 \mathrm{~B}$ term, i.e., with only 12 or 24 weeks of on-campus academic experience, they need very early exposure to practical activities to address this issue. This is particularly important since employers hiring students at 
this level look for those with at least a basic mechanical skillset.

To develop and implement a hands-on experience for 400 first year MME students one must overcome significant hurdles related to timing and resource allocation. Several solutions were considered to increase student practical knowledge and experience within the first year ME and MTE concepts courses, ME and MTE100. These included integrating an increased portion of practical material during design graphics instruction, delivering hands-on demonstrations during class and (the most daunting) devising a machine shop based activity in which every student would participate. All three solutions have been implemented, but it is the methodology and outcomes of the third hands-on solution that will be the focus of this paper.

\section{BACKGROUND}

\subsection{Technical Experience of Students Entering Engineering}

That the vast majority of students in the mechanical/mechatronics stream of engineering lack practical mechanical skillsets becomes apparent from the opening class of the first week of lectures. Students in engineering design graphics are informally surveyed (with a show of hands) about their previous experience, which indicates that most have not developed basic technical skills in mechanical drafting and computer aided design.

A quantitative explanation for the lack of practical experience in pre-university education is beyond the scope of this paper. However, with the broad range of factors potentially at play, it is expected that the root cause is complex and nuanced. For example, the decreasing availability of technical programs in secondary education and a strong focus on obtaining high grades in math and sciences to meet university requirements may lead students towards courses with predominantly theoretical curricula. As well, parents' occupations, urban vs. rural upbringing, the current popularity of video games, along with gender and cultural issues may all play a role.

\subsection{Early Instruction and the Need for Hands- on Activity}

The impetus to develop a practical experience for all students stemmed from the lack of screw thread knowledge:

An instrument drawing of a simple part assigned during the first week of classes contained a threaded hole callout, as seen in Fig. 1.

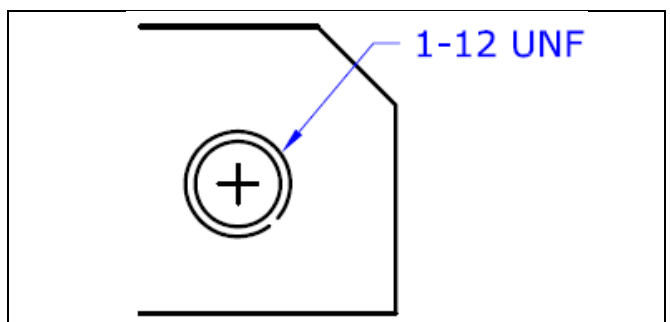

Figure 1: Thread designation

Few students understood this designation, prompting incorporation of screw thread terminology into the graphics course material. However, this added breadth did not provide any insight on how a screw thread is fabricated. Thus, an in-class thread drilling/tapping demonstration developed to include one or more student volunteers. Based on the popularity of this demonstration, it was quickly realized that all class members might find value in carrying out this simple activity, spurring an initiative to provide every student with this experience.

The initial implementation strategy was designed to expose all students to the Engineering Student Machine Shop where they would each get an opportunity to drill and tap holes into a long strip of metal. This would not only provide hands-on experience with machine tools, but would expand the students' understanding of the machine shop and its broad possibilities. To spark deeper and sustained interest in mechanical skills development, it was proposed that students should come away from the activity with a keepsake that would serve as both a reward and a reminder of their efforts. Hence, the hole tapping/drilling activity evolved into a task that would allow students to develop a personal item, i.e., a keychain.

\subsection{Peer Intimidation}

The impact of peer intimidation on whether students with minimal ("inferior") technical skillsets will pursue skills training or take on projects with technical requirements is becoming increasingly clear to the author. However, this does not appear to be widely covered in the literature, at least when peer intimidation in engineering at the university level is reviewed. We have found that students with strong technical backgrounds, and particularly those who are demonstrative of their greater experience, can be intimidating to colleagues who lack even basic technical skills. Unfortunately, it only takes one "showboat" to discourage several less confident students from participating in hands-on activities. If the disparity in skill level between students isn't addressed quickly, some begin to question their ability to catch up to their more skilled counterparts, and whether engineering is the right fit for them. One student reported being afraid to get involved in hands-on activities due to a selfperceived lack of skill and a reluctance to talk with her peers about anything technical for fear of embarrassing 
herself. This intimidation was an additional motivation to provide a means of building confidence and to level the technical playing field for the many students who entered engineering with some trepidation or uncertainty.

\subsection{Clinic Initiative at UWaterloo}

The MME department at UWaterloo is in the process of implementing a new teaching initiative known as the Engineering Clinic. The goal of the clinic is to enhance student learning through increased practical experience and bridge the gap between theoretical and real world experience. In the words of the director: "A fundamental outcome of the clinic is to enhance student skill, confidence and experience through hands-on activities. This can best be achieved if students genuinely (and safely) are able to do everything themselves" [ 8].

The keychain thread-tapping project was seen as an aligned precursor activity in the development of the clinic program.

\section{RESULTS AND DISCUSSION}

Implementing a hands-on activity designed to include all first year students posed significantly more challenges than anticipated. As the project developed several obstacles arose. Every student related component had to be multiplied by $360-400$, i.e., the size of the student population, to fully appreciate the resources required. The keychain activity requirements were categorized as follows (see Table 1): design of the keychain, keychain blank manufacture, equipment requirements and procurement, student throughput including the task flow, supervision by technical staff.

Table 1: Keychain Hands-On Activity Requirements

Design of Keychain

Design of CNC Machining Fixture

Keychain Blank Fabrication

Equipment \& Consumables Procurement

Student Shop Throughput

Scheduling

Supervisory Staff Assignment and Scheduling

Student Shop Fabrication setup

Activity Machining Guide Creation

Student Pre-Workshop Safety training

Setup, Student Session, Take down

The Keychain thread tapping activity was implemented during the fall term of 2012 then improved and re-introduced during the following fall term in 2013.

\subsection{Implementation One: Fall 2012}

As planned, this machining activity would be completed in a group format under the supervision of
MME technical staff. An alternative was to have students enter the student machine shop at their own convenience over the term. However taking this singular approach for the 360 students would command too much of the student shop staff members' time (who were non-MME employees). It was decided that each week a subset of the class, i.e., a group of 10 students, would leave a communication for the student shop. This set a time constraint of 50 minutes to service these 10 students. Roughly 360 students participated in the activity over a 12 week term, requiring 36 sessions, 3 sessions per week.

\subsubsection{Design of Keychain and Blank Fabrication.}

The large number of students put constraints on time and resources, limiting what could be accomplished during the session. This directly impacted the design alternatives for the keychain. Through a period of design abstraction and synthesis the selected alternative was a keychain designed in two identical sections, joined by three representative fasteners. The fasteners would introduce students to a range of common thread series and impart an understanding of the tap drilling and threading process. The threads would include (i) a metric thread, (ii) an imperial (ASME) coarse thread (iii) and an imperial fine thread series. The upper keychain blank was designed to expose students to different types of fastener head profiles and means of surface mounting these fasteners. Included were a flat head screw with a countersink, a socket head with a counterbore and a button head with a basic through hole. The details are shown in Figure 2.

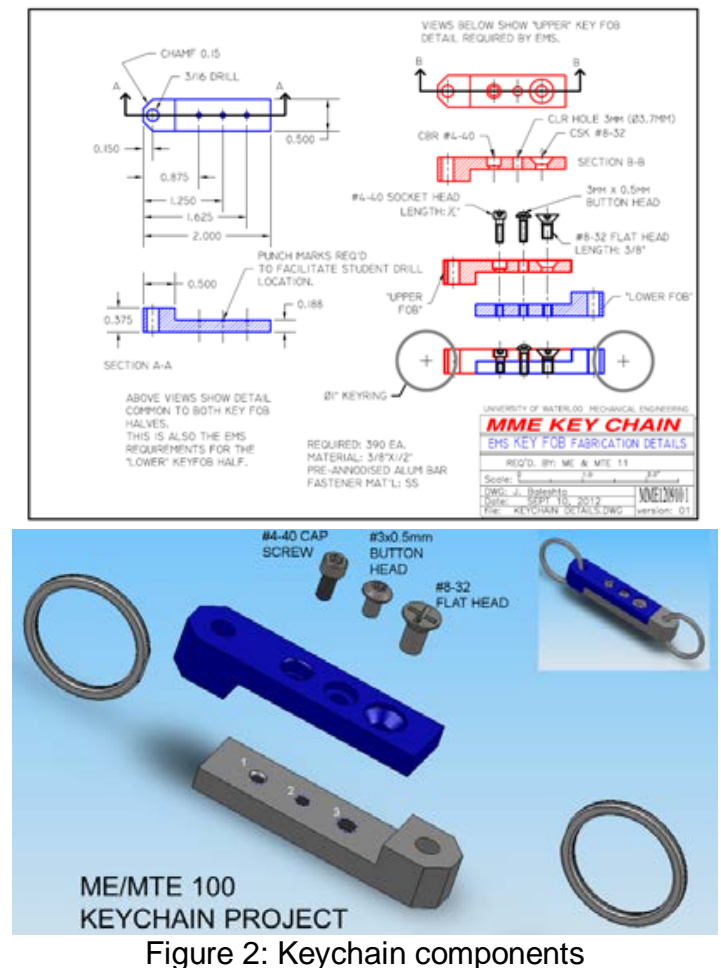

Figure 2: Keychain components 
The keychain was designed to have a key ring at each end, to attach keys at one end and at the opposite end to a lanyard, popular with students. To reduce the manufacturing time for the required 720 blanks (2 per keychain) the machinists made requests: (i) cut the blanks from readily available, easy to machine rectangular aluminum bar stock (selected size: 1/2x3/8”, 12.7x9.5mm), (ii) do all machining operations on one surface only to avoid the additional operations of flipping the 760 specimens for further machining, (iii) design the upper and lower blanks to have the same shape for easier computer numerical controlled (CNC) machine programming. A blank was designed to accommodate the above constraints (Figs. 2 \& 3).

The blank fabrication began by cutting the bar stock into 2 inch $(51 \mathrm{~mm})$ lengths then machining, two blanks at a time on a CNC mill. The milling process included the counterbore, countersink and through hole for the fasteners. The lower blank had machined centre-drilled locations to facilitate tap drilling by the students. A "MME" designation was engraved on the blanks. Due to time constraints, the blanks were not anodized but completed by sand blasting to mask surface nicks and imperfections. Figure 3 shows fabricated keychain blanks from this first offering.

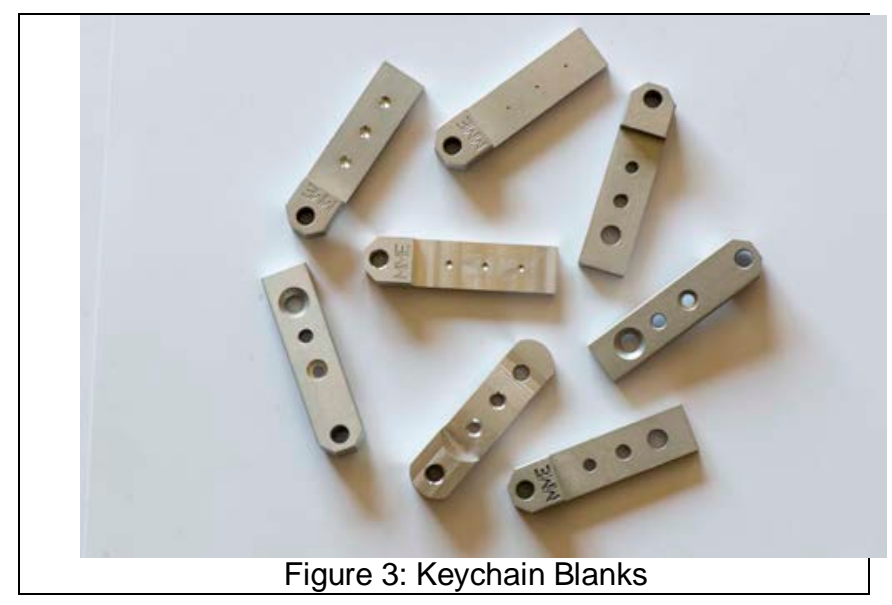

3.1.2 Equipment Requirements and Procurement. The activity location was planned for the UWaterloo Faculty of Engineering Student Machine Shop. Three drill presses and three thread tapping devices were needed for the machining operations. This equipment was borrowed for this first implementation. A dedicated bench space of 38 linear feet $(11.5 \mathrm{~m})$ was required in the busy student shop. This had to be carefully negotiated. Consumable items included drill bits, taps, lubricant, stainless steel fasteners and key rings. Due to availability, the \#8 fastener was switched to a coarse thread series (\#8-32).

This initiative was seen as an entry level machining activity and deliberately avoided the requirements, costs and complexities of using lathes and milling machines for this large group of students. However, in an effort to spark a desire to learn to use this equipment and increase hands-on competency, the lathes and milling machines were in-use in the student shop for MME students to observe while they were doing their keychain activity. .

3.1.3 Work Flow, Safety and Supervision. The student machining throughput, which increased from 10 to 15 students per group, was supervised by three MME technical staff members. Three drill presses were sequentially arranged, each with the correct tap drills preinserted into the chucks. In a similar arrangement, tapping fixtures with the three required thread taps were aligned. This activity exposed large numbers of inexperienced students to machining equipment, making safety a prime concern. Before allowing entry to the machine shop, the students were required to wear safety glasses, assessed for appropriate clothing and hair retention, and lectured on safety by a supervisor. They then progressed in an "assembly line" fashion to drill the appropriate tap sized holes, then tap the threads. When these (6) activities were completed they moved to an assembly area where they secured the fasteners and rings. Virtually all 360 students were able to complete this exercise during the term. Completing the drilling and tapping activities in the allotted time and ensuring resources were in place was initially a challenge. However, ongoing refinements to the process improved the throughput rate and sessions could be comfortably completed by all students in the allotted 50 minutes.

3.1.4 First Offering Outcomes: To learn from the outcomes of the first implementation, students were informally queried and post-session de-briefing meetings were held with both the keychain fabricators and the activity supervisors. Most students acknowledged that they had never drilled a hole in metal before nor tapped a thread and appreciated the opportunity. Even the more experienced students enjoyed the exercise and felt they got something out of it. The key chains became a hallmark and source of pride for that year of engineers. However there were weaknesses to be resolved. For example, after drilling and tapping the holes, some students wondered "what specifically did we just do?" It seemed pre-setup of the equipment, while efficient, circumvented some valuable learning. Also the technical staff felt overwhelmed and underappreciated for this additional, supervisory role and felt they lacked general faculty support. Also, borrowing equipment for the entire term was an imposition that could not be repeated. Dedicated equipment must be purchased. The keychain blank fabricators reported that they needed a greater leadin time for this magnitude of work and suggested that a fixturing jig be designed to allow several blanks to be machined concurrently. 


\subsection{Year Two Implementation: Fall 2013}

The second keychain activity implementation attempted to address the areas of improvement cited from the initial offering. The enrollment in ME and MTE now totaled 400 students.

The keychain again used the two part blank arrangement with all required machining on one surface only. A holding fixture was designed, shown in Fig. 4, to allow milling of 32 blanks concurrently with one setup on the CNC mill. The fabrication of this fixture took effort but it was a significant improvement over the "two-up" jig used previously. It is intended to re-use this jig in future years. Within the constraints of the retaining jig it is intended that each year of students will have a unique design for their keychain as a form of class identity.

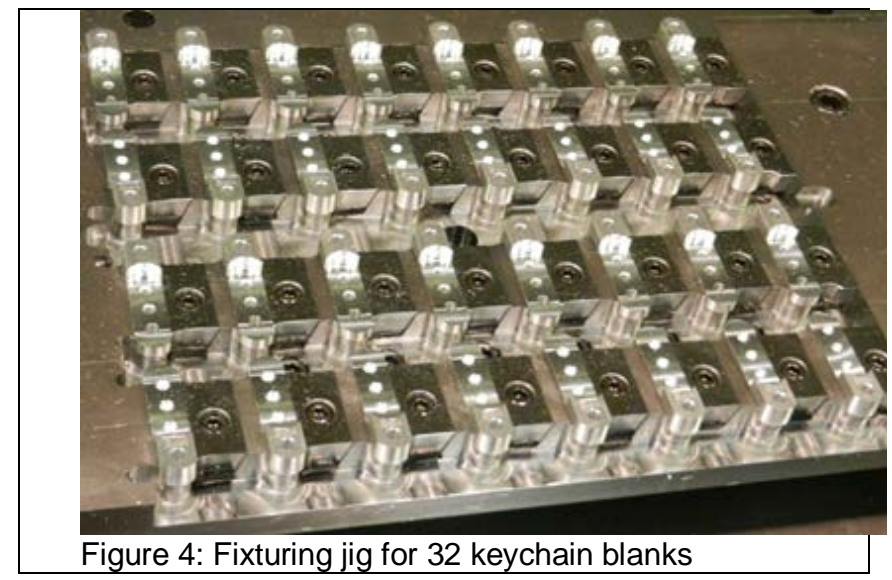

An identical shape for the bottom and top blanks was again designed for efficiency. The locational hole depths were increased as this was identified as a problem area for many students. As an added activity a through hole was provided in the upper blank for the \#8-32 fasteners but without the former countersink as this would be machined by students. It is estimated that the addition of the fixture and the ability to machine 32 blanks concurrently (shown in Fig. 5) decreased the machining time from 105 to 40 seconds per keychain blank.

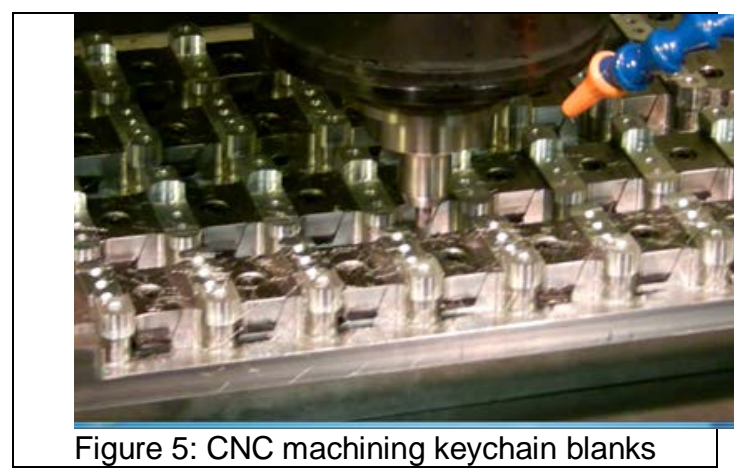

To enhance the keychain aesthetics a deep anodizing procedure was used, with a different colour for the top and bottom blanks. Figure 6 shows the new keychain blank design.

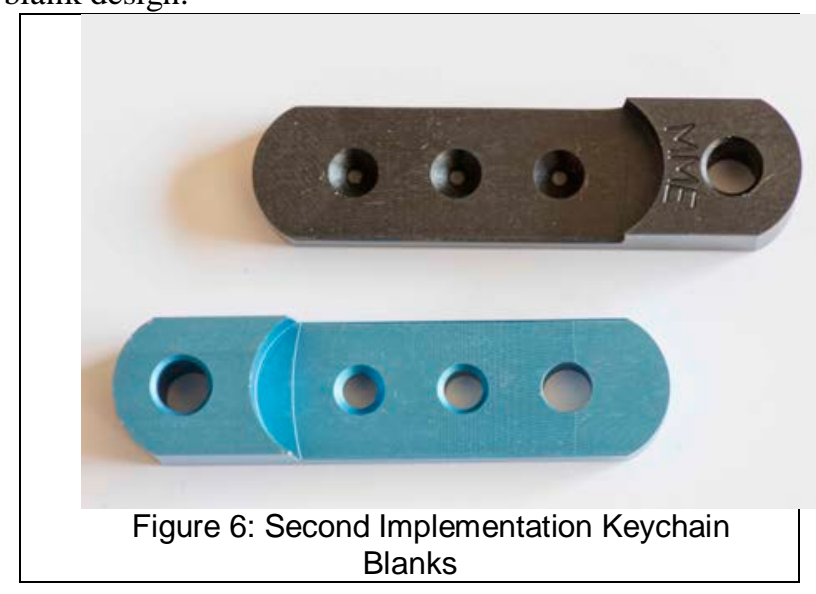

The first implementation outcome highlighted the need to improve student understanding of the machining procedures they performed. A pre-workshop thread terminology assignment was created based on specific details of the keychain. Students were required to determine the tap drill sizing required, countersink and counterbore dimensions, and list basic safety requirements.

Students were also coached on the appropriate behavior (i.e., respect and humility) when interacting with the technical staff supervising their activity. They were told that if staff members are treated with respect they will in turn be willing to share their knowledge and mentor students. The opposite will occur when arrogance and a lack of respect is shown. The students were advised that this behavioral approach should also extend to technical staff during their cooperative work terms.

The assembly line style used during the first offering was replaced with discrete work stations" where a small group of (2-3) students could do all the drilling and tapping at one location. This would require more hands-on involvement from students. Five stations were established, requiring procurement of drill presses, tapping fixtures, and clamping vices for each. Customized "parts blocks" were fabricated to hold and organize the various drills, taps and countersink. These were useful and worth mentioning as they minimized loss and mixups for this large student influx.

Staffing was increased to have one instructor at each of the five stations. This was achieved by retaining three staff members and adding a teaching assistant and the design graphics course instructor. All regular MME technical staff members were expected to participate in these sessions on a rotating basis. Staff member participation was vital to the success of the sessions. Unexpectedly, scheduling the staff members and getting them to "buy into" a new, recurring task was one of the 
most challenging aspects of this implementation. To expedite participation the staff technical manager switched this from a "voluntary" to a mandated activity.

The student enrollment grew from 360 to 400 for the second implementation. The group sizes were kept to 15 students per session as was the three sessions per week schedule.

3.2.1 Second Implementation Results: The workstation approach was perceived to be a clear improvement over the previous assembly line style, albeit more time consuming. The students were immersed in the process to a greater extent. For instance they had to insert their own drill bits into the drill press chuck and taps into the tapper, seemingly trivial procedures but clearly one that most had never undertaken before. Figure 7 shows a keychain session in progress.

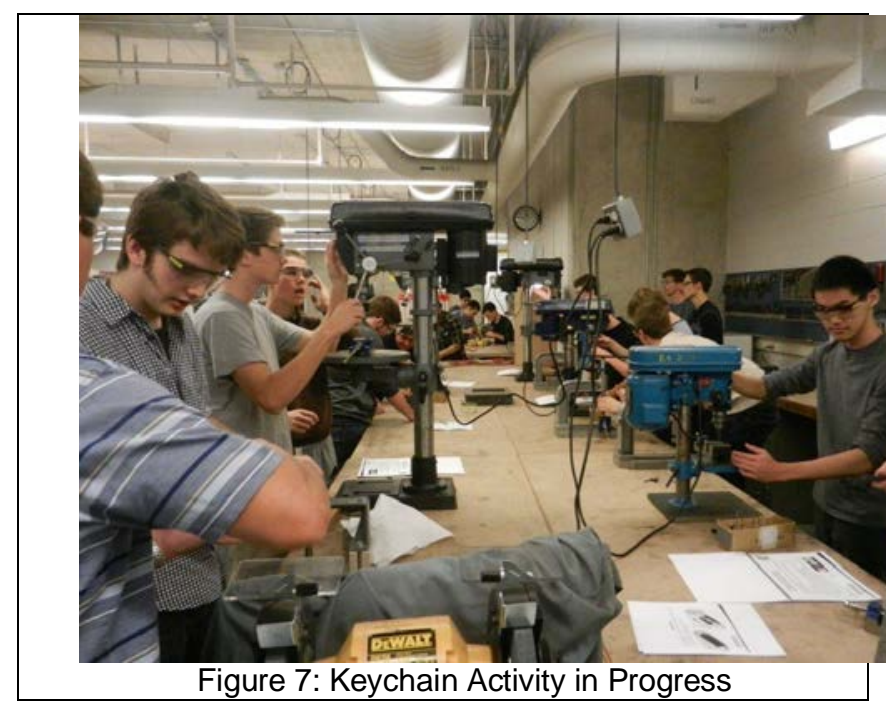

Regular participation by the course instructor in these sessions allowed for first-hand observation of the level of hands-on competency of the students, their performance with the activity and their reaction to it. Instead of lecturing to $120+$ class sizes the instructor invested an hour in close connection with a small group of 3 students. Perera, Quinlivan, and Zastavker (2013) cite numerous positive benefits of instructor one-to-one interactions with students [5].

Counterbore drilling was a positive addition. As well, students were given the option of stamping letters on their finished keychain or returning to the shop for this activity (time permitting). The allotted hour was very full but, as with the first implementation, ongoing improvements during the weekly sessions increased efficiency and reduced session time requirements.

The stainless steel fasteners, standard with the first offering were changed to plain black. Then, throughout the term if a student did particularly well on an aspect of the concepts course the teaching assistants would replace one of their black keychain fasteners for silver, and then gold plated as a student incentive and reward. Figure 7 shows a completed keychain.

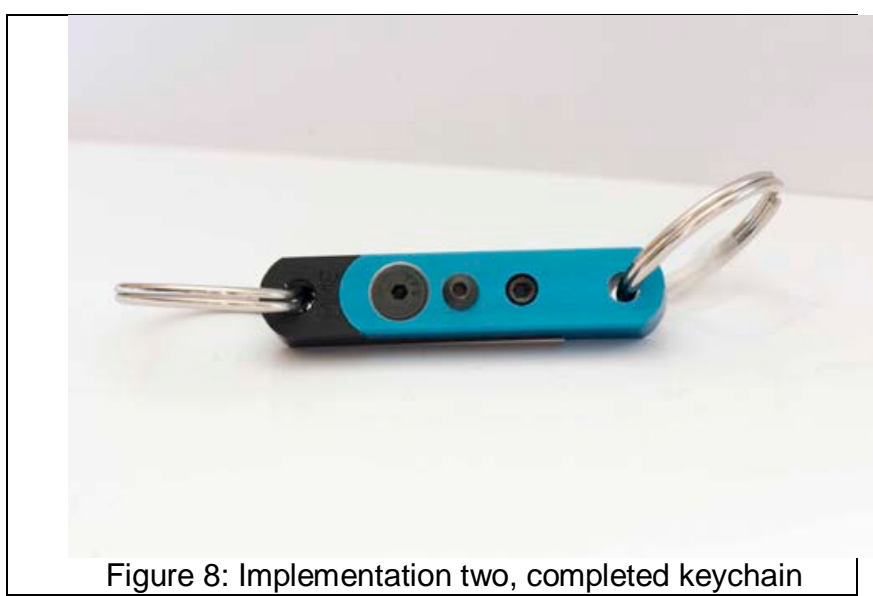

\section{CONCLUDING REMARKS}

Implementing even a small hands-on activity for large class sizes commands a significant amount of effort. However, even a small hands-on activity was appreciated by the students and brought students with weaker technical backgrounds in from the sidelines. This was observed to have had a positive impact on skills development and de-marginalizing students with weaker technical backgrounds.

This initiative required substantial resources in terms of physical space, equipment procurement, planning and staffing.

The activity reinforced the perception that many first year engineering students have minimal practical skills, and further that they want this experience and enjoy hands-on activities. Several favourable outcomes were observed:

This exercise decreases the gap between the experienced and inexperienced students who may have not have had the same opportunities for practical experience. They see that other students also lack these skills, and they are not alone. Students are introduced to the machine shop and get excited by the thought of doing other projects. The intent is that students will gain enough confidence to try more complex machining, and other practical activities. One example: an MTE student reported that the keychain experience provided her with the confidence and desire to join a student team (the Formula SAE Race Car). She then chose her first cooperative work term with the electrical and mechanical fabrication of a solar vehicle.

Students are instructed on safety measures when working with machinery. They are closely watched and corrected as necessary. It is expected that these work-safe procedures will carry over to future machining activities. 
This experience provided an early exposure to group work providing an opportunity to connect and cooperate with other classmates.

The reward of the keepsake keychain, each design unique to their year adds to the student class identity, as well as to each student's personal accomplishment and pride.

Teaching assistants reported that replacing the standard black keychain fasteners with silver and gold fasteners as an incentive to reward notable student performance in the concepts course was effective.

Direct participation with the machining sessions allowing the course instructor to spend direct time with individual students was a "win-win” for both parties.

Coaching students on the appropriate behavior to use with technical staff had a positive outcome. MME Technical Staff members recounted that the students were generally well behaved, and overall the sessions went well. This soft skill approach should serve them well during their work terms and professional lives.

One MME professor expressed an interesting viewpoint that hands-on activities such as the keychain could lead to an increased willingness of students entering graduate studies to consider research that contains an experimental component; in his experience many now shun experimental work due its practical skill set requirements.

Technical Staff "buy in", crucial to the successful rollout of this activity, was not easy to achieve and should not be taken for granted. Staff cooperation can make or break a project of this nature. Measures to foster staff compliance are worthwhile, and departmental recognition for this work is essential. A gradual realization that this (and other engineering clinic activities to follow) will continue to be part of their regular work will hopefully mean a paradigm shift for the staff.

The keychain activity is expected to continue in the MME department at UWaterloo. Other UWaterloo programs have requested this activity, and it has now enjoyed additional implementations in specialty programs such as Women in Engineering and Waterloo Unlimited.

\section{Acknowledgements}

The author would like to acknowledge the contributions made by Mr. Robert Wagner, MME technical staff member, Charles Boyle and Rick Forget of the Engineering Machine Shop, Michael Wilson for his photography, engineering librarian Rachel McNeil and Page Burton for her review.

\section{References}

[1] Bruce Carlson, Paul Schoch, Michael Kalsher, Bernadette Racicot, "A motivational first-year electronics lab course”,
Journal of Engineering Education, October 1997, pp. $357-$ 362

[2] Lawrence E. Carlson and Jacquelyn F. Sulivan, "Hands-on engineering: learning by doing in the integrated teaching and learning program”, Int. J. Engng Ed. Vol. 15, No. 1, pp. 12, 1999

[3] Roydon Fraser, "ME 2013 Exit Survey Presentation", personal communication, University of Waterloo, April 2014.

[4] Stephanie S. Ivey, Mihalis M. Golias, Paul Palazolo, Stephen Edwards, and Patrice Thomas, "Attracting students to transportation engineering, gender differences and implications of student perceptions of transportation engineering careers",Transportation Research Record: Journal of the Transportation Research Board, No. 2320, Transportation Research Board of the National Academies, Washington, D.C., 2012, pp. 90-96. DOI: 10.3141/2320-11

[5] Perera, J. I., Quinlivan, B. T., \& Zastavker, Y. V. (2013). "Faculty perceptions on undergraduate engineering education in first-year engineering, physics, and mathematics courses." in 120th ASEE Annual Conference and Exposition, (Atlanta, 23-26 June 2013) 15 pp. 2013

[6] S. D. Sheppard and R. Jenison, Freshmen engineering design experiences: an organizational framework, International Journal of Engineering Education. 1996.

[7] Andrew Trivett, Stephen Champion, "Using online openinnovation challenges to introduce design in first-year engineering courses”, AC2012-5195 in American Society for Engineering Education, (San Antonio 10-13 June 2012), 10 pp., 2012

[8] Andrew Trivett, “MME Engineering Clinic: Implementation Plan”, personal communication University of Waterloo 25 March 2014

[9] Varbanescu, R., Dobrescu, R., Varbanescu, A. L., \& Cazan, A., "Teaching data acquisition systems - A hands-on approach." in 15th IMEKO Symposium on Novelties in Electrical Measurements and Instrumentation in Parallel with the 12th Workshop on ADC Modelling and Testing, September 19-21, 2007 